\title{
INTRODUÇÃO AO PENSAMENTO REFORMACIONAL DE HERMAN DOOYEWEERD
}

INTRODUCTION TO HERMAN DOOYEWEERD'S REFORMATIONAL THINKING Davi Tavares Viana ${ }^{17}$

17 Graduado em Direito pelo Centro Universitário de João Pessoa (2008). Advogado. Email: davitviana@hotmail.com 


\section{RESUMO}

Este artigo apresenta o pensamento introdutório de Herman Dooyeweerd (1894-1977), jusfilósofo membro da Academia Real Holandesa de Ciências e Artes pouco conhecido no Brasil, porém notabilizado internacionalmente por significativa contribuição para a filosofia e outras áreas do conhecimento. $\mathrm{O}$ artigo está dividido em quatro momentos. No primeiro, apresentam-se como possíveis soluções à crítica positivista ao discurso metafísico dooyeweerdiano a resposta realista (pós-positivista) defendidas por Alvin Plantinga, William Alston e Richard Swinburne. No segundo, serão tratados sucintamente as principais contribuições do seu pensamento manifestadas através da filosofia da ideia cosmonômica cujo principal objetivo foi a tentativa de reformar a razão. Logo em seguida, será apresentada a crítica do filósofo americano PhD pela Universidade de Havard, Nícolas Wolterstorff, ao filósofo holandês. E, por fim, visando conferir um efeito prático à teoria reformacional dooyeweerdiana será indicada uma possível solução para a polaridade existente na filosofia política entre o poder político e a justiça.

\section{PALAVRAS-CHAVE}

Herman Dooyeweerd; metafísica; filosofia analítica da religião; filosofia da ideia cosmonômica; reforma da razão.

\section{ABSTRACT}

This article presents the introductory thought of Herman Dooyeweerd (1894-1977), a member of the Royal Dutch Academy of Sciences and Arts little known in Brazil, but internationally renowned for his significant contribution to philosophy and other areas of knowledge. The article is divided into four moments. In the first one, they present themselves as possible solutions to the positivist critique of the dooyeweadian metaphysical discourse and the realist (post-positivist) answer defended by Alvin Plantinga, William Alston and Richard Swinburne. In the second, the main contributions of his thought expressed through the philosophy of the cosmological idea whose main objective was the attempt to reform reason will be briefly treated. Soon after, the critic of the American philosopher PhD by the University of Havard, Nicholas Wolterstorff, will be presented to the Dutch philosopher. Finally, in order to give a practical effect to the Doe-Reedian reform theory, a 
possible solution will be indicated for the polarity existing in the political philosophy between political power and justice.

\section{KEYWORDS}

Herman Dooyeweerd; metaphysics; analytical philosophy of religion; philosophy of the cosmological idea; reform of reason.

\section{INTRODUÇÃO}

O presente artigo adota a perspectiva qualitativa com ênfase na metodologia bibliográfica com uma abordagem eminentemente teórica. Trata-se, na verdade, de pesquisa introdutória acerca do complexo pensamento de Herman Dooyeweerd (1894-1977), jusfilósofo holandês, doutor em Direito, presidente por vários anos da Sociedade Holandesa de Filosofia do Direito e reitor da Universidade Livre de Amsterdã por duas vezes e cujo auge da carreira foi o exercício, de 1948 até o seu falecimento, da digna função de membro da Academia Real Holandesa de Ciências e Artes.

Dooyeweerd sendo ao mesmo tempo "herdeiro e criador da tradição 'neocalvinista' reformacional" é um autor cujas obras e pensamento ainda são pouco conhecidos no Brasil. Sua introdução no mercado literário brasileiro, por exemplo, deu-se recentemente no ano de 2010 através da publicação pela editora Hagnos de sua obra In the twilight of the western thought, em português, intitulada: No crespúsculo do Pensamento (CARVALHO, 2010, p. 7).

Dooyeweerd produziu um sistema filosófico denominado de "filosofia reformacional" ou "filosofia da ideia cosmonômica" cujo núcleo do pensamento está na rejeição do absolutismo da razão, isto é, de que a razão seja a fonte última da verdade. Existem algumas obras publicadas em periódicos acerca do pensamento introdutório dooyeweerdiano que são utilizadas neste ensaio, inclusive, como referencial teórico e bibliográfico, contudo o artigo ora apresentado difere dos demais na medida em que aborda o debate filosófico experiencialista inglês como possível resposta racional à crítica da tradição kantiana "pós-metafisica", que rejeita absolutamente a teorização sobre conceitos elementares para a percepção da realidade.

Muito embora se desconheça qualquer atribuição de ausência de cientificidade ao pensamento de Dooyeweerd e 
considerando que a filosofia da ideia cosmonômica parte de um referencial de verdade metafísico, calha uma apresentação do pensamento experiencialista inglês capaz de acentuar ainda mais a cientificidade do jusfilósofo holandês. Outrossim, o artigo contribuiu na medida em que abarca, através do método de revisão bibliográfica, ainda que de maneira introdutória, diversas concepções, inclusive críticas e práticas, acerca do pensamento dooyeweerdiano.

Através de notas de rodapé, tenta-se contextualizar historicamente e conceituar elementos importantes para uma melhor compreensão do texto. Ademais, muito embora este não seja o objeto do estudo, espera-se que o leitor seja capaz de elaborar possíveis respostas a perguntas intrigantes da atualidade, tais como: ciência e fé cristã são incompatíveis? Ou a ciência e a fé podem ser mantidas em compartimentos separados? (BANCEWICZ, 2013).

O objetivo do artigo, portanto, é contribuir para a difusão acadêmica introdutória de um teórico holandês cuja obra permite à sociedade compreender, sob o ponto de vista filosófico, aspectos teóricos e práticos do pensamento e da realidade sem a necessidade de um apelo para o inócuo proselitismo religioso cristão.

\section{CONTEXTO HISTÓRICO E RELEVÂNCIA DO PENSAMENTO DOOYEWEERDIANO}

A formação familiar e profissional de Herman Dooyeweerd foi profundamente influenciada pelo protestantismo ${ }^{18}$ calvinista $^{19}$, posteriormente denominado na

\footnotetext{
18 "A reforma protestante foi, incontestavelmente, a primeira revolução social do mundo moderno... revolução, mais no sentido francês do que britânico", pois "contribuiu, de modo direito ou indireto, para a transformação da sociedade europeia, não só no campo religioso, como também no terreno político e econômico, ao produzir fundas alterações no ideário, nas instituições de organização social e na prática de vida" (COMPARATO, 2006, p. 167-169).

${ }^{19}$ João Calvino (1509-1564). "O segundo grande Reformador da religião cristã no século XVI acentuou as características de racionalismo e individualismo, que iriam marcar a vida ética no mundo pós-medieval... É pela razão que cada homem pode entrar diretamente em contato com o seu Criador, sem carecer de intermediação da Igreja e dos sacramentos... Foram esses aspectos racionais e individualistas da doutrina calvinista, aplicados à tarefa de metódica transformação do mundo pela atividade profissional de cada ser humano no
} 
Holanda de movimento neocalvinista atribuído ao seu líder Abraham Kuyper ${ }^{20}$, fundador da instituição de ensino cristão denominada Universidade Livre de Amsterdã (1880).

Kuyper foi Primeiro-Ministro dos Países Baixos entre 1901 e 1905 e tinha um forte anseio de presenciar a igreja, as instituições de ensino e o Estado "exercendo seus poderes e obedecendo a seus limites dentro daquilo que ele mesmo cunhou de 'esfera de soberania"' (ALMEIDA OLIVEIRA, 2006, p. 38), muito embora tenha lutado pela "fundação de uma universidade cristã que fosse independente tanto da igreja como do Estado" (RAMOS; FREIRE, 2014, p. 19).

Influenciado pelos dois principais movimentos do século XIX, o neocalvinismo holandês ${ }^{21}$ e o idealismo alemão ${ }^{22}$,

cumprimento de sua vocação de glorificar a Deus, que as diversas confissões cristãs de obediência calvinista desenvolveram ao máximo... O ponto de partida da ética calvinista é um pessimismo absoluto quanto à natureza humana. Por força do pecado, ela é corrompida e nada produz que não mereça condenação. Por conseguinte, todo bem que fazemos vem de Deus" (COMPARATO, 2006, p. 175-176).

20 "For Kuyper, every Christian called to be an agent of the Kingdon of Jesus Christ, wherever they are called by God to serve. The system of though that Kuyper developed was an elaborate spelling out of how we are to understand this call to Kingdon service. How are we to understand God's intentions in creating the world and - in response to the human rebellion that thwarted God's creating purposes - in sending the divine Son to reclaim the world that had been so corrupted by sin?". (MOUW, 2011, p. 5).

21 "O neocalvinismo foi um movimento protestante de reforma cultural e religiosa, na Holanda, que procurou interpretar a visão reformada calvinista do mundo e da vida em um contexto. Iniciado por Guillaume Groen Van Prinsterer (1801-1876), aristocrata e historiador, arquivista da casa de Orange-Nassau, o movimento chegou a dominar a vida cultural e política da Holanda, no final do século XIX e início do século XX, por meio de Abraham Kuyper, teólogo, jornalista, educador, político, e primeiro-ministro de 1901 a 1905. Kuyper sempre afirmou ser um seguidor fiel de Calvino, (...). Bastaria dizer, por agora, que a soberania de Cristo sobre todos os aspectos da vida humana era o centro da visão neocalvinista e foi a inspiração de um grande movimento de renovação cristã da cultura holandesa com desdobramentos na educação, na academia, na política e na igreja." (CARVALHO, 2010, p. 7ss).

22 "O Idelismo alemão surgiu em 1781, com a publicação da Crítica da razão pura de Kant, e terminou cinquenta anos mais tarde, com a morte de Hegel. (...) Kant, Fichte, Schelling $e$ Hegel - os quatro mais importantes idealistas alemães - pavimentaram o caminho para Marx e Kierkegaard, a fenomenologia e o existencialismo, a teoria crítica e o pósestruturalismo (...) A causa filosófica imediata ao Idealismo alemão foi o ceticismo de David Hume (1771-1776) (...) Mas a tendência cultural mais ampla que deu origem à Crítica da razão pura e, oito anos mais tarde, à Revolução Francesa, foi a insistência do iluminismo em substituir a aceitação pré-moderna da injustificada autoridade com a demanda moderna por uma justificativa racional e a liberdade" (DUDLEY, 2013, p. 11). 
Dooyeweerd elaborou a filosofia da ideia cosmonômica, fruto em um rigoroso edifício teórico-sistemático baseado no diálogo com toda a tradição filosófica, com a teologia católica e protestante e com os mais diversos campos da ciência (CARVALHO, 2010).

Para Carvalho (2010), a obra De Wijsbegeerte der Wetsidee, ou A filosofia da ideia de lei é considerada o mais importante escrito filosófico de um cristão protestante nos últimos 200 anos. Referida obra foi publicada em 1953 na língua inglesa em quatro volumes de quase duas mil páginas sob o título $A$ New Critique of Theoretical Thought.

Acerca da relevância do autor, Carvalho (2010, p. 6) assevera que:

Mais do que introduzir alguns valores cristãos na universidade, Dooyeweerd se lançou ao ambicioso projeto de reformar a razão, de reformar a tradição filosófica e científica do ocidente a partir de seu coração espiritual, e de reencontrar a ligação perdida entre pensamento teórico e religião.

Por fim, a importância de se conhecer as ideias do autor encontra relevância e atualidade na medida em que, como observou Smith in Carvalho (2010, p. 37), "O pensamento cosmonômico, de fato, antecipou muitas observações de Gadamer, Derrida ou Foucault". Além do mais, o argumento dooyeweerdiano impressiona no discurso acerca da relatividade racional do pensamento teórico "em relação aos compromissos pessoais e sociais dos homens que pensam". ${ }^{23}$ Tal discurso, inclusive, é pertinente para o hodierno debate entre modernistas e pós-modernistas na medida em que, sem imergir no irracionalismo, relega o absolutismo da razão. ${ }^{24}$

\footnotetext{
23 "O que não significa que seja possível classificar Dooyeweerd como um pós-moderno. Na verdade, como já foi observado mais de uma vez, o movimento neocalvinista, como um todo, jamais foi coerentemente moderno. Seria um paroxismo descrevê-lo, agora, como pós-moderno, quando se aprofundou e ganhou maturidade para seguir o seu próprio caminho. De fato, a melhor forma de descrever a filosofia reformacional seria a de classificá-la como um projeto paramoderno. Um projeto que ouve e leva a sério as questões modernas (que, em seguida, tornaram-se "pós" ou "hiper" modernas), mas que tem a sua própria raiz, a sua própria agenda e suas próprias respostas" (CARVALHO, 2010, p. 37)

24 "Dooyeweerd recusa-se a admitir, que a razão seja a fonte última da verdade, como o quiseram os modernos; mas recusa-se igualmente a negar a existência e o valor da verdade, como o querem os pós-modernos" (CARVALHO, 2010, p. 38)
} 


\section{UMA RESPOSTAÀ CRÍTICA POSITIVISTAAO PENSAMENTO METAFÍSICO}

O núcleo central do pensamento dooyeweerdiano é metafísico diante do fato de que tudo o que cerca a vida e a realidade possuem natureza religiosa, pois volta-se de alguma maneira para a origem de todas as coisas (Deus), seja para honrálo ou não. Deste modo, para que se possa avançar no presente estudo é necessário, antes de mais nada, ultrapassar a crítica positivista ao pensamento metafísico.

Segundo Kant ${ }^{25}$ seria problemático atribuir um caráter científico à metafísica, muito embora fosse possível visualizá-la como forma de estudo da ação moralmente correta. Outrossim, tem-se o empirismo radical de Alfred Ayer, segundo o qual seria improvável a linguagem tratar de assuntos teológicos, uma vez que as afirmações metafísicas, além de estarem fora do alcance da linguagem, careceriam de alguma experiência sensorial relevante (conteúdo empírico) (PORTUGAL, 2010).

Ao escrever sobre "a tensão dialética no humanismo moderno" abordando a primazia da natureza (Descartes, Hobbes e Leibnz), a primazia da liberdade (Locke, Rousseau e Kant) e a síntese dialética (idealismo pós-kantiano), Dooyeweerd assevera que:

(...) o conflito interno entre o motivo da natureza e o motivo da liberdade no ponto de partida religioso do humanismo levou Kant a uma visão de mundo e da vida fortemente dualista. Natureza e liberdade foram acentuadamente separadas uma a outra. E essa separação correspondeu à separação kantiana entre fé e ciência que, por sua vez, tinha um pano de fundo religioso" (DOOYEWEERD, 2010, p. 128).

\footnotetext{
25 “(...) a metafísica foi entendida por Kant na Crítica da Razão Pura como a ciência que estuda as condições formais que tornam possível o conhecimento dos objetos e não como o conhecimento dos objetos em si mesmos. Na medida em que o conhecimento da realidade depende de que essas condições formais sejam preenchidas pelo conteúdo de uma intuição, a metafísica enquanto teologia ou ontologia se tornam problemáticas, pois a razão investiga esses objetos de modo puramente especulativo, sem qualquer conteúdo ou controle da experiência" (PORTUGAL, 2010, p. 81).
} 
Deste modo, seria possível contornar o problema exposto através da resposta realista ${ }^{26}$ ao positivismo da filosofia analítica da religião? A resposta é sim. O pensamento realista, aqui denominado "pós-pós-metafísico" ou "pós-positivista"27, trata-se resumidamente das ideias defendidas por Alvin Plantinga, William Alston e Richard Swinburne segundo os quais a experiência 28 religiosa não apenas teria sentido, mas seria perfeitamente possível falar de Deus no sentido metafísico tradicional do teísmo.

De acordo com Portugal (2010), Plantinga ${ }^{29}$ sustenta incoerência no argumento de Kant por dois fundamentos: primeiro, porque negar conhecimento sobre Deus já seria um tipo de conhecimento sobre Deus. Segundo, porque o conhecimento sobre todo e qualquer objeto sofreria influência do limite da capacidade humana de pensar e perceber o mundo. Assim, porque

\footnotetext{
${ }^{26}$ A resposta "não-realista" defendida por Wittgenstein e D. Z. Phillips reside no fato de que a linguagem religiosa não se refere ao mundo, como acontece com a linguagem científica, entretanto desempenha um papel importante de guia existencial e ético.

27 "A crítica à metafísica iniciada por Hume e Kant teve continuação no positivismo lógico, no início do século XX, e este movimento intelectual constituiu um capítulo fundamental da chamada filosofia analítica, que surgiu com os trabalhos de Gottlob Frege e Bertrand Russell sobre os fundamentos lógicos da matemática, no final do século XIX. Assim, "pensamento pós-metafísico" significa nesta tradição, especialmente no caso do positivismo, o pensamento que rejeita qualquer pretensão de argumentar sobre conceitos fundamentais para o conhecimento da realidade, pois entende que cabe às ciências naturais, com o emprego do método experimental, o conhecimento do mundo e das relações entre os objetos. Além disso, o pensamento pós-metafísico inaugurado pelo positivismo lógico questiona fortemente, como veremos abaixo, a possibilidade de qualquer conhecimento de um suposto Ser Primeiro. Pensamento pós-metafísico, nesse contexto, é aquele que nega à metafísica qualquer valor cognitivo e que põe em questão a teologia como empreendimento intelectual. (PORTUGAL, 2010, p. 82).

28 "A noção de experiência religiosa, um dos temas mais importantes da filosofia da religião de Schelling tem atualmente um lugar especial na reflexão filosófica sobre a religião no universo cultural de língua inglesa. Pode inclusive falar de movimento nesse debate chamado 'experiencialismo' que inclui autores como William Alston, Caroline FranksDavies, Jerome Gellman, Alvin Plantinga, Richard Swinburne e Keith Yandell, todos contemporâneos, ativamente engajados nesta discussão, mas muito pouco conhecidos da comunidade filosófica brasileira. Um traço distintivo dos experiencialistas é sua preocupação não apenas com a descrição deste fenômeno em termos filosóficos, mas principalmente com emprego deste conceito na justificação racional da crença de que Deus esse existe. Em certo sentido, podemos dizer que se trata de uma continuação em bases modernas do tradicional problema das relações entre fé e razão, abordado por autores como Agostinho, Tomás de Aquino, Ibn Sina e Saadia Ibn Joseph na idade média" (PORTUGAL, 2004, p. 138).
}

${ }^{29}$ Ver PLANTINGA, Alvin. Warranted Christian Belief. Oxford: Oxford. University Press, 2000. 
não aplicar esta restrição limitada da capacidade humana ao conhecimento de Deus? ${ }^{30}$

Já William Alston se concentrou na teoria da justificação das crenças perceptuais ${ }^{31}$ formada a partir da experiência religiosa. No entender de Portugal (2010), para Alston, a ocorrência mental decorrente da percepção religiosa independe da iniciativa do sujeito, pois pressupõe que algo externo apareça a ele. Ensina Alston que a percepção como fonte de informação independe do conhecimento do processo como ela se opera. Outra refutação importante reside na possibilidade de Deus se apresentar ao ser humano dentro dos limites da sua capacidade de percepção, não sendo necessário o conhecimento pleno da essência divina, mas de certas características comunicáveis como bondade e poder. Em suma, não se pode concluir que Deus não existe se há percepção através da experiência religiosa de sua existência (PORTUGAL, 2010).

Adotando a tese da subdeterminação da teoria pela experiência - posição estabelecida na filosofia da ciência do século XX, Swinburne observa que os dados empíricos não são suficientes para tornar uma hipótese mais provável do que outra, até porque é possível um número de explicações potencialmente infinito compatíveis com os mesmos dados da experiência. Isto é, qualquer argumento científico e de senso comum pressupõe elementos que estão para além dos dados empíricos, "pressupõem, com o perdão da palavra, 'bases metafísicas"' (PORTUGAL, 2010, p. 95). Por isso

\footnotetext{
30 "(...) segundo Plantinga, pode-se dizer que as experiências religiosas - isto é, o conjunto de estados de coisas, eventos ou fatos, enquanto apreendidos pelo sujeito, que põem em atividade o sensus divinitatis - concorre para a garantia da crença teísta, na medida em que aquelas compõem um ambiente cognitivo adequado. Se este estiver em condições normais, ou seja, ordenado conforme o modo para o qual o sensus divinitatis foi projetado, então o resultado será uma crença provavelmente garantida sobre Deus" (PINHEIRO, 2010, p. 108)

31 "A ideia de Alston é explicar a justificação das crenças por meio de um modelo que ele denomina de fundacionalismo modesto. Nesse modelo, algumas crenças teriam como fonte a experiência e algumas outras teriam como fonte outras crenças. Além disso, determinadas crenças poderiam fornecer e receber suporte de outras, possibilitado uma sustentação mútua entre elas e fornecendo adequada justificação ao conjunto como um todo. Esse é o modelo de justificação epistêmica que Alston atribui ao sistema de crenças do cristianismo. Nessa concepção, as experiências misticas produzem crenças com base experiencial que vão oferecer suporte às crenças baseadas em afirmações explanatórias que, por seu turno, aumentam a confiança nas crenças oriundas da experiência". (ALSTON apud CAVALCANTI, 2010, p. 15).
} 
que a rejeição da metafísica pelo positivismo além de enaltecer indevidamente o conhecimento científico impediu de se atribuir significado à linguagem científica. $O$ fato de a metafísica discutir os pressupostos daquilo que as ciências teorizam é motivo suficiente para cultivá-la, entretanto, isso não significa dizer que a ciência dependa da metafísica para sua atividade (PORTUGAL, 2010).

Outrossim, utilizando o teorema de Bayes ${ }^{32}$ como recurso formal, Swinburne defende o teísmo com base na aplicação do raciocínio científico descrito em termos indutivos e probabilísticos. A partir dos argumentos cosmológico, teleológico e do problema do mal, Swinburne formula dados que aumentam ou diminuem a probabilidade da hipótese que Deus existe. O teísmo, portanto, seria um pressuposto da própria explicação científica, pois torna mais provável os fatos que a ciência ou não tem como explicar ou cuja explicação resulta numa compreensão geral de mundo muito mais complicada (PORTUGAL, 2010).

Apresentadas as possíveis respostas à crítica positivista ao pensamento metafísico, passemos à breve apresentação da filosofia da ideia cosmonômica de Dooyeweerd.

\section{A FILOSOFIA DAIDEIA COSMONÔMICA:TEORIAE PRÁTICA}

O elemento central da filosofia do pensador holandês se refere à ordem divina da criação e à tripla ideia de Lei ${ }^{33}$ (origem do

\footnotetext{
32 "Admitindo-se a ideia de se atribuir valores probabilísticos a hipóteses ou crenças, este teorema nos diz que o grau de confirmação de uma hipótese é dado pela estimativa prévia de sua probabilidade e pelo seu poder explicativo em relação aos dados relevantes para a sua avaliação. Assim, o detetive que está tentando descobrir o autor do crime parte da estimativa inicial de uma das hipóteses rivais e considera o quanto esta explica os dados disponíveis... O lugar da experiência religiosa na epistemologia da crença teísta de Swinburne éde mais um fenômeno que é melhor explicado pela tese de que existe um Deus tal como postulado pela crença comum das grandes religiões monoteístas (um ser pessoal incorpóreo, onipotente, onisciente, perfeitamente bom, onipresente, eterno e digno de adoração). Na verdade, trata-se não apenas de 'mais um fenômeno', mas do argumento decisivo em favor do teísmo, que faz o balaço final de probabilidade, com o qual ele conclui seu livro mais importante, The Existence of God, pender em favor da tese de que Deus existe" (PORTUGAL, 2004, p. 147-148).

33 "A noção de lei criacional é central na filosofia de Dooyeweerd. Tudo na criação é sujeito a lei de Deus, e a lei é o limite lelo entre Deus e a criação. A lei se diferencia no tempo em diversas leis que governam as esferas modais (leis modais) $e$ as estruturas de individualidade (leis típicas). Sinônimos escriturísticos para leis são 'ordenança', 'decreto', 'mandamento', 'palavra', etc. Dooyeweerd enfatiza que a lei não está em oposição d̀ liberdade; antes, é a condição para verdadeira liberdade, porque é ela o que habilita as
} 
mundo, totalidade e coerência da diversidade) estruturando e envolvendo todo o universo. A ideia de ordem da criação regida por uma Lei universal se daria através da origem da totalidade de um universo diversificado e coerente em suas estruturas internas e externas.

De acordo com Almeida Oliveira (2006), o salto de originalidade de Dooyeweerd, portanto, está na epistemologia da filosofia da ideia cosmonômica segundo a qual não existe conceitos científicos desvinculados de uma visão de mundo précientífica, até porque o sentido de todo conceito tem fundamento em outros conceitos. Seriam estes conceitos prévios denominados por Dooyeweerd de base religiosa do pensamento teórico fruto do wetsidee $^{34}$, ou "ideia cosmonômica" ou ideia de Lei ou ideia básica transcendental, que nada mais é do que a resposta a três perguntas fundamentais: (i) qual a origem da realidade cósmica? (ii) como explicar a ideia de totalidade do universo? (iii) como elucidar a ideia de diversidade coerente da realidade temporal cósmica?

Em outras palavras, a base religiosa de todo e qualquer pensamento seria identificada com apoio na resposta do sujeito ao wetsidee, restando, portanto, demonstrada a não veracidade do dogma da neutralidade religiosa da razão ${ }^{35}$ e o equívoco do reducionismo científico às dimensões lógicas e metalógicas da realidade.

\footnotetext{
diversas funções temporais do homem. As leis lógicas, por exemplo, não são 'limites' para o pensamento em sentido negativo, mas suas condições de possibilidade". (DOOYEWEERD, 2014, p. 143)

34 "O termo holandês original para IDEIA COSMONÔMICA, literalmente 'ideia-de-lei'. A filosofia de Dooyeweerd éconhecida na Holanda como Wijsbegeerte der Wetsidee ('filosofia da ideia de lei'). A ideia deriva do lugar centra da LEI criacional no pensamento de Dooyeweerd". (DOOYEWEERD, 2014, p. 154).

35 "A tradição filosófica ocidental como um todo sempre trabalhou sobre a premissa de que a razão filosófica ou científica nos dá um acesso privilegiado à realidade na exata medida em que é capaz de se evadir de compromissos extrateóricos - de pressuposições culturais, sociais ou religiosas. Quanto a isso, Dooyeweerd faz uma pergunta simples, mas constrangedora, às escolas de pensamento que reivindicam "neutralidade religiosa": se o pensamento teórico tem seu ponto de partida na razão autônoma (como se alega), por que as disputas entre escolas, tanto na ciência como na filosofia, nunca são resolvidas aí, no nível teórico? Por que elas jamais superam suas diferenças no campo da razão, apesar de alegarem todas a mesma neutralidade essencial? No mínimo, ele nos diz, temos o dever tornar a autonomia da razão em um problema crítico, no sentido técnico do termo." (CARVALHO, 2010, p. 28)
} 
Como se vê, Dooyeweerd sugere, com assento na antropologia agostiniana, que a condição primária de todo ser humano é orientar-se em direção a uma origem, ou seja, o homem entendido com vontade e busca. E a origem de todas as coisas jamais poderia fazer parte do cosmo, mas fora do cosmo. Daí a admissão irrestrita do Teísmo no sentido calvinista como ideia de origem cósmica: Deus soberano, princípio da ordem cósmica, além de toda a lei, mas sustentador de todas as leis (CARVALHO, 2005).

Para Dooyeweerd, a totalidade da realidade seria composta de quinze aspectos modais ${ }^{36}$, também chamados de esfera de lei ou esfera de significado: o numérico, o espacial, o cinemático, o físico, o biótico, o psíquico ou sensitivo, o lógico ou analítico, o histórico, o lingüístico ou simbólico, o social, o econômico, o estético, o jurídico, o ético ou moral e o pístico (aspecto da fé) (ALMEIDA OLIVEIRA, 2006).

Se por um lado cada um dos quinze aspectos modais tem a sua "esfera de soberania" ${ }^{37}$ com um núcleo de significado irredutível, por outro há uma relação intermodal dinâmica de significado entre os quinze aspectos que Dooyeweerd chama de "esfera de universalidade"38. Na esfera de universalidade não

\footnotetext{
36 "Conforme o pensamento de Dooyeweerd, o tempo cósmico se expressa através da diversidade modal. Assim como um prisma que reflete a luz do sol num espectro de sete cores diferentes, sendo cada uma destas sete cores refrações diversas de um único feixe de luz solar, e estando estas sete cores luminosas entremeadas numa profunda coerência luminosa umas com as outras, assim também ocorre com o tempo em relação à totalidade de significado da criação. Esta totalidade de significado ao passar pelo "prisma" do tempo se divide em quinze aspectos ou modos distintos de significado da realidade que permanecem numa mútua coerência de significado" (ALMEIDA OLIVEIRA, 2006, p. 85).
}

37 "A expressão inglesa sphere sovereignty (também vertida para o português como 'esfera de soberania') traduz a expressão de Kuyper, souvereiniteit in eigen kring, que significa que as várias esferas distintas da autoridade humana, como família, igreja, escola e negócios, têm cada uma a sua própria responsabilidade e poder decisório, que não podem ser usurpados por aqueles que tem autoridade em outra esfera, como por exemplo, o Estado. Dooyeweerd retém esse sentido kuyperiano original, mas estende o seu uso para significar também IRREDUTIBILIDADE das esferas modais, tornando assim o princípio das 'esferas de soberania' um princípio cosmológico. Esse é o princípio ôntico sobre o qual o princípio social de Kuyper se baseia, visto que cada uma das 'esferas' sociais mencionadas é qualificada por uma diferente modalidade irredutível" (WOLTERS In: DOOYEWEERD, 2014, p. 151)

38 "No inglês, sphere universality, ou 'universalidade de esfera'. A contrapartida de SOBERANIA DAS ESFERAS. É o princípio segundo o qual todas as modalidades estão intimamente conectadas uma às outras em uma coerência inquebrável. Assim como 'soberania das esferas' ressalta a diferença e a irredutibilidade dos aspectos modais, a 'universalidade modal' enfatiza que cada um deles depende de todos os outros para o seu 
existe autossuficiência por parte de cada aspecto modal, uma vez que cada um deles aponta para todos os demais e com eles se relaciona enriquecendo assim o significado individual de cada esfera. Por exemplo, conforme ensina De Almeida Oliveira (2006), a Fé com sua esfera própria de soberania jamais pode ser reduzida à razão ou qualquer um dos aspectos modais da esfera de universalidade, entretanto a compreensão do inteiro significado da fé depende de uma interpretação dinâmica da fé com os demais aspectos.

Ao desenvolver a crítica transcendental do pensamento teórico, Dooyeweerd realizou diálogo crítico com o neokantismo ou neocriticismo alemão atribuindo um alcance mais extensivo ao termo "transcendental" cunhado pelo próprio Kant. De acordo com o filósofo holandês, o pensamento kantiano se equivoca na medida em que atribui à razão o ponto de partida que possibilitaria todo pensamento. Para Dooyeweerd, o ponto de partida se encontraria, na verdade, no coração fundamentalmente religioso (ALMEIDA OLIVEIRA, 2006).

O "eu" tomado em si mesmo jamais pode ser o ponto de partida último do pensamento teórico sem que haja a devida relação com a sua verdadeira Origem ou pseudo-origem. Isso implica dizer que um falso conhecimento acerca da Origem comprometerá toda epistemologia mediante distorções e antinomias (ALMEIDA OLIVEIRA, 2006).

De acordo com o pensamento Dooyeweerdiano, o mundo seria representado, portanto, por dois tipos de motivos básicos religiosos representados por antíteses religiosas irreconciliáveis: (1) motivo básico revelacional que reconduz as ações do homem para a glória de Deus; (2) motivo básico da apostasia onde o homem deifica aspectos relativos da criação em rebelião contra Deus (ALMEIDA OLIVEIRA, 2006).

Enquanto que por um lado Dooyeweerd descarta qualquer possibilidade de síntese religiosa através da demonstração dos pressupostos centrais das duas visões de mundo fruto da antítese religiosa irreconciliável, por outro lado manteve um diálogo crítico com as escolas filosóficas não-cristãs,

significado. Isso é evidenciado pelas ANALOGIAS na ESTRUTURA MODAL de cada uma das modalidades". (ibidem, p. 154). 
oportunidade em que desenvolveu e aprimorou seus temas à luz dos pressupostos revelacionais.

Ao realizar a crítica da estrutura interna do pensamento teórico, Dooyeweerd afirmará, de acordo com Almeida Oliveira (2006), que não é possível haver verdadeira filosofia ${ }^{39}$, isto é, reflexão sobre a totalidade do mundo, sem uma reflexão crítica sobre o "eu". Mas como se daria esta autorreflexão? Dooyeweerd responde afirmando que o "eu" resta absolutamente vazio e sem significado quando desconectado de sua origem. Deste modo, é necessário conectar o autoconhecimento humano ao conhecimento de sua origem ou pseudo-origem, uma vez que todas as coisas criadas apontam para além de si mesmas à procura de plenitude de significado do mundo ${ }^{40}$.

Referido raciocínio pode levar o leitor dooyeweerdiano desatento a supor que ao ser humano, então, caberia utilizar a teologia para se alcançar o real autoconhecimento.

(...) isso também se constituiria em um autoengano. Pois como ciência dogmática dos artigos de fé cristã, a teologia não é mais capaz de conduzirnos a um real conhecimento de nós mesmos e de Deus do que a filosofia ou as ciências especiais que estão

\footnotetext{
39 "O pensamento filosófico está limitado à ordem temporal da experiência humana, assim como estão as ciências especiais. Nessa ordem temporal, a existência humana apresenta se apenas em uma rica diversidade de aspectos, e não naquela unidade central radical à qual denominamos nosso eu ou ego... O mistério do eu humano é que ele é, de fato, nada em si mesmo; quer dizer, ele é nada enquanto tentamos concebê-lo à parte de suas três relações centrais as quais, unicamente, fornecem-Ihe sentido. Primeiro, nosso ego humano relaciona-se com a nossa existência temporal total e com a nossa experiência integral do mundo temporal como seu ponto de referência central. Segundo, ele se encontra, de fato, em uma relação comunal essencial com o ego de seus semelhantes. Terceiro, ele aponta para além de si mesmo em direção à relação central com sua origem divina, em cuja imagem o homem foi criado." (DOOYEWEERD, 2010, p. 260-261).

40 "O homem contemporâneo pergunta por sua identidade; a sua angústia maior é a de não saber de si mesmo. Entre as causas dessa condição está a crescente massificação $e$ tecnicização do homem, que aparece cada vez mais despersonalizado e alienado de experiências comunitárias reais. Ao mesmo tempo, a vida se torna mais superficial com a dissolução dos valores espirituais que alimentaram o Ocidente em suas origens. (...) Somente no encontro com a sua verdadeira origem o homem ocidental encontrará renovação para a sua cultura e o pensamento no ocidente. A igreja cristã poderia apresentar essa saída, lamenta ele, não houvesse ela mesma aderido a antropologias não bíblicas" (CARVALHO, 2005, p. 35)
} 
interessadas no estudo do homem... Jesus Cristo nunca condenou os escribas e fariseus por sua falta de conhecimento teológico-dogmático"

(DOOYEWEERD, 2010, p. 254).

Sendo assim, como seria possível alcançar o autoconhecimento no entender de Dooyeweerd? A resposta está no sentido radical de criação, queda e redenção que norteia todo o seu pensamento filosófico, que parte do argumento de que Deus revelou o homem ao próprio homem quando o criou a sua imagem e semelhança.

Como criador, Deus se revela como a origem absoluta de tudo o que existe fora de si mesmo. Não há poder no mundo que seja independente Dele... E assim como Deus é a origem absoluta de tudo o que existe fora de si mesmo, Ele criou o homem como um ser em quem a inteira diversidade dos aspectos e faculdades do mundo temporal estão concentradas no centro religioso de sua existência. Esse centro é aquele ao qual denominados nosso eu, e o qual as Escrituras sagradas chamam, em um sentido religioso, de coração. Como o assento central da imagem de Deus, o ego humano foi imbuído com um impulso religioso inato a fim de concentrar todo o mundo sob o serviço de amor a Deus (DOOYEWEERD, 2010, p. 259)

Considerando, portanto, que a imagem de Deus no homem tem relação direta com a raiz de sua existência temporal total, a "ilusão surgida no coração humano, quando o eu humano creu possuir uma existência absoluta como o próprio Deus" resultou na morte espiritual da raça humana uma vez que "o eu humano não é nada em si mesmo" (DOOYEWERD, 2010, p. 260).

O fato é que o total rompimento com a queda do eu com - Criador não destruiu o centro religioso (raiz) da existência humana e o "seu impulso religioso inato de buscar sua origem absoluta", contudo o tem conduzido para direções falsas da realidade com status de absoluto, "desviando-o em direção ao 
mundo temporal com sua rica diversidade de aspectos, os quais, entretanto, têm apenas um sentido relativo" (DOOYEWEERD, 2010, p. 260). Na verdade, para Dooyeweerd, apenas a reconexão com o Criador pode trazer ao homem o autoconhecimento e a sua salvação, daí a importância da redenção não dualista ${ }^{41}$.

\section{A CRÍTICA DE WOLTERSTORFF}

Nícolas Wolterstorff é um filósofo americado $\mathrm{PhD}$ pela Universidade de Havard e cujo projeto epistemológico se pauta na teorização orientada para a práxis. Sua crítica à Dooyeweerd está na suposta letargia da teorização e sistematização da filosofia neocalvinista que, em virtude de seu caráter abstrato, não foi capaz de reagir e denunciar as mazelas sociais oriundas do sistema capitalista. Para Wolterstorff, o mandato cultural neocalvinista na qualidade de princípio determinante não fornece uma direção prática para o conhecimento, motivo pelo qual deveria ser substituído pelo shalom.

Ao elaborar a teoria sobre ética social, Dooyeweerd sugere uma abordagem sociológica bíblica que englobe a integralidade do ser humano no âmbito do trinômio criação-queda-redenção. Essa abordagem deve ser feita em total interação com o conceito de mandato cultural dado ao homem na criação, obliterado com a queda e necessitado de restauração em Cristo (CARVALHO, 2005).

A lógica do conceito de mandato cultural seria a seguinte: Deus concedeu ao homem a responsabilidade de cultivar e proteger a criação na qualidade de Seu vice gerente através das normas e diretrizes sociais do Reino. Logo, competiria ao homem anunciar a salvação e desenvolver com sabedoria, justiça, paz e equidade a criação sob o ponto de vista social e cultural, agindo com responsabilidade na medida em que imita a justiça de Deus, restando inconteste que o mandato cultural pressupõe a harmonia

\footnotetext{
41 "Apenas por meio de Jesus Cristo, Palavra encarnada e Redentor, a imagem de Deus tem sido restaurada no centro religioso da natureza humana. A redenção por Jesus Cristo em seu sentido bíblico radical significa o renascimento de nosso coração e deve se revelar no todo de nossa vida temporal.... Essa falsa divisão da vida humana em uma esfera natural e outra supranatural se tornou o ponto de partida do processo de secularização que resultou na crise da cultura ocidental, em seu desenraizamento espiritual... A razão humana não é uma substância independente; é, antes, um instrumento. O eu é o músico oculto que se utiliza dele. E o motivo central que governa tanto o pensamento quanto o próprio ego humano é de natureza religiosa central". (DOOYEWEERD, 2010, p. 264).
} 
social. É preciso registrar que tal pensamento decorre da teologia calvinista que tem como fundamento o preceito bíblico da responsabilidade cristã, onde se combate a alienação através da interação com a sociedade (CARVALHO, 2005).

Em resumo, Deus estabeleceu leis criacionais para o cosmos e dentro destas leis coube ao homem a responsabilidade cultural de modelar a história governando a criação através do mandato cultural. Contudo, em virtude de uma cosmovisão privada e distorcida deste mandato, evidenciou-se na história da humanidade as mazelas sociais.

Partindo da doutrina de Piacente Júnior (2012), de acordo com o pensamento social de Wolterstorff, o neocalvinismo não possui a capacidade de influenciar uma reforma social através de uma força cultural engajada. Assim, com a finalidade de resolver o problema da ética social, sugere o filósofo americano a prática do shalom cuja origem decorre do diálogo crítico entre duas propostas de pensamento: o neocalvinismo holandês e a teologia da libertação. O shalom, portanto, ao assumir o compromisso acadêmico com a teorização orientada para a práxis tomaria o lugar do mandato cultural na medida em que faria oposição veemente à opressão e à injustiça propagadas no modelo econômico capitalista.

O mérito da proposta do shalom está na sua relevância e atualidade em alertar os cristãos acerca do efetivo papel social que as igrejas devem ter perante a sociedade através de ações concretas que possam influenciar e/ou modificar os contextos circunvizinhos. Contudo, não se verifica na ética social proveniente do shalom um caráter metafísico de orientação cristã. Logo, qualquer sociólogo não cristão chegaria à mesma conclusão de Wolterstorff sem qualquer amparo escriturístico. Neste ponto, Dooyeweerd agiria com mais precisão ao propor uma ética social que emana das Escrituras (PIACENTEJUNIOR, 2012).

Além do mais, no entender de Piacente Junior (2012), Wolterstorff falha ao não questionar os pressupostos religiosos idolátricos tanto da teologia da libertação quanto do marxismo. Tratar a libertação social, e não a libertação do pecado, como fim último a ser alcançado pelo ser humano, fragiliza a teoria social do shalom. 


\section{JUSTIÇA SOCIAL E PODER POLÍTICO}

Ao versar especificamente sobre o Estado, Dooyeweerd defende que sua tarefa (função qualificante) é a implantação da justiça pública ${ }^{42}$. Contudo, o Estado não poderia interferir em outras esferas de soberania "naquilo que diz respeito à autonomia própria de cada esfera" (CARVALHO, 2005, p. 37), uma vez que cada esfera revela uma maneira própria de poder, diferenciada por sua função guia. ${ }^{43}$

A justiça, na condição de esfera de soberania cujo núcleo de sentido seria a "retribuição", significa uma intuição fundamental da estrutura do mundo, dada na experiência ordinária. Por isso que "as pessoas 'sabem' muitas vezes quando há ou não justiça, de modo intuitivo" (CARVALHO, 2005, p. 38).

No entender doyeweerdiano, justiça é uma práxis que precisa ser realizada. Logo, o julgamento jurídico, por sua vez, precisa de algo a mais do que simplesmente uma norma jurídica. Precisa, na verdade, de um contexto humano capaz de fornecer uma noção positiva de Justiça. O conceito teísta positivo de justiça possui base conceitual na ordem criacional daí o seu conceito pluralista e complexo. O pluralismo e a complexidade do conceito residiriam exatamente no fato de a lei criacional de Deus

\footnotetext{
42 "Conquanto Dooyeweerd e Max Weber destaquem a exposição do poder formativo do Estado, "há uma diferença fundamental entre Weber e Dooyeweerd no que diz respeito ao papel desempenhado pela legitimidade. Em Weber, o poder coercitivo do Estado parece "um fim em si mesmo". Contudo, para Dooyeweerd, esse poder é algo que diz respeito 'meramente ao fundamento do Estado, e não a seu destino'. Em outras palavras, para Weber, o 'poder da espada' é também o que qualifica a finalidade do Estado. Para Dooyeweerd, ele apenas funda o Estado (função fundante), estado o seu destino final (função qualificante) relacionado à 'formação de uma comunidade de direito público na qual a 'justiça pública' é estabelecida'". (RAMOS e FREIRE, 2014, p. 30).
}

${ }^{43}$ Ao definir a noção de "soberania das esferas", Kuyper assim a definiu: "De uma perspectiva calvinista, entendemos, então, que a família, as empresas, a ciência, a arte, etc. são todas esferas sociais que não devem sua existência ao Estado e que não derivam sua lei de vida da superioridade do Estado, mas que obedecem a uma autoridade superior interna à sua área; uma autoridade que governa [internamente a elas], pela graça de Deus, tal como o Estado o faz [internamente à sua própria esfera]". (Ricard J. Mouw, Abraham Kuyper: A short and Personal Introduction. Grand Rapids: Eerdmans, 2011, p. 51 citado por RAMOS e FREIRE, 2014, p. 20.). "Essa noção de soberania interna de cada uma das esferas em seu próprio domínio tem um componente normativo: o Estado deve abster-se de governar famílias, empresas, universidades e igrejas, por exemplo. Caso contrário, cada uma dessas associações distorcerá sua missão original e passará a ser um instrumento do poder público" (ibid. p. 21). 
estabelecer corpos sociais (esferas soberanas) cada qual com sua normatividade própria.

Conforme visto, a soberania de uma esfera reside na hipótese de ela mesma se desenvolver finalisticamente de acordo com as normas que the são intrínsecas. Desta maneira, despiciendo o esforço do Estado tentar regular pela força uma estrutura social pertencente a outra esfera, pois não pode alterála ontologicamente. Para Carvalho (2005), o poder político e a realização da justiça social precisam observar quatros princípios básicos. O primeiro princípio se trata da preservação das esferas de soberania jurídica na sociedade. Conquanto seja papel crucial do Estado implementar a justiça pública, não pode ele dominar todas as áreas da vida social. Compete ao Estado, portanto, para implementar a norma de sua esfera e harmonizar a vida humana, reconhecer os limites das esferas de soberania jurídica (base ontológica de todo direito).

O segundo princípio é o impedimento da tirania de uma esfera social sobre outras. Isso significa que o Estado não pode ser "mínimo" ao ponde de permitir que esferas distintas interfiram nas demais limitando sua atuação. O Estado nestes casos deve intervir e estabelecer limites entre as esferas para que não haja danosa interferência. O autor apresenta como exemplo os excessos cometidos pela esfera econômica que estimula a acumulação excessiva de capital e a má distribuição de renda.

O terceiro princípio aborda o impedimento de injustiça dentro de uma esfera de soberania. Existem autoridades designadas para coordenar e garantir a justiça peculiar de cada esfera. Entretanto, caso estas autoridades venham a ferir as normas internas prejudicando direitos jurídicos dos membros de uma determinada esfera jurídica, é dever do Estado intervir para impedir o ato injusto ou tentar a sua reparação. E o último princípio seria a reação social de desobediência civil diante de um Estado injusto. Esta atitude, é importante ressaltar, seria necessária não para negar o Estado, mas para auxilia-lo na implementação de sua tarefa.

Para Gordon Spykman in Carvalho (2005), as Escrituras e a doutrina calvinista apresentam expressamente uma nítida conexão entre a implementação da justiça e a defesa do pobre, uma vez que a melhor forma de garantir a justiça pública é 
simplesmente procurar na sociedade indícios de opressão, seja em que nível for.

O núcleo da esfera econômica, portanto, no entender de Dooyeweerd é a mordomia, significando dizer que a acumulação de capitais não pode ser um fim em si mesma, mas uma implicação na redistribuição voluntária, e não imposta pelo Estado, da renda com o propósito de aumentar a qualidade de vida de toda a sociedade (CARVALHO, 2005).

\section{CONSIDERAÇÕES FINAIS}

A teoria de Dooyeweerd tentou criar um sistema de pensamento que apresentasse soluções para dilemas da humanidade através de uma interpretação da realidade sob um ponto de vista biblicamente orientado. O objetivo do presente artigo foi o de exatamente trabalhar de maneira introdutória a teoria de seu pensamento associada à práxis.

Dentro de um contexto pós-moderno, pluralista e multicultural, ao construir um edifício teórico-sistemático baseado nos pressupostos centrais da Escritura (leia-se, Bíblia), o pensamento dooyeweerdiano contribui para a reflexão filosófica fundamental acerca da origem do homem e sua finalidade dentro de um sistema cósmico absolutamente coerente em sua infinita diversidade.

O jusfilósofo holandês, com muita propriedade, traz à reflexão, por exemplo, a incoerência pós-moderna de se partir sempre do pressuposto dogmático de relativização da verdade como se essa assertiva, em si mesma, fosse a própria verdade. Não se desconhece o fato de que a predominância universal de uma suposta verdade poderia acarretar no mundo plural e multicultural injustiças e processos acentuados de exclusão e conflitos, contudo, é preciso verificar duas questões importantes.

A primeira delas é que um cristão eticamente orientado não possui qualquer legitimidade e/ou autoridade escriturística para impor suas convicções a terceiros. Segundo, nem a filosofia nem a ciência poderão impedir que a razão crítica deixe de se debruçar sobre a resposta do sujeito ao wetsidee. A natureza investigativa do ser humano torna-se covarde e simplista ao relegar esta resposta ao "não sei" diante do pressuposto 
dogmático pós-moderno de que não existe uma verdade. Ora, esta "verdade" em si deve ser contestada como o foram as verdades do cristianismo medieval, da natureza e da razão, sob pena de a humanidade ocidental terminar sua melancólica jornada racional no paradigma da verdade das não verdades.

A fundamentação teórico-filosófica de Dooyeweerd abre um caminho crítico para o diálogo do cristianismo com a esfera científica com propriedade e argumentação metodológica sem que tenha que se agarrar em argumentos meramente espirituais ou dogmáticos religiosos.

Do mesmo modo, auxilia as igrejas cristãs do Brasil a estarem atentas aos movimentos do Estado que podem intervir indevidamente na sua esfera de soberania ou na esfera de soberania de instituições importantes, a exemplo da família. Banda outra, se de um lado os cristãos precisam estar munidos de conhecimento bíblico e científico para responder questões espirituais, políticas, sociais, culturais, etc., por outro necessitam estar em estado de alerta acerca da real influência da igreja na sociedade atual para que não se construam feudos acadêmicos totalmente alheios à dinâmica individual e coletiva da sociedade e do Estado.

Como se vê, a obra do jusfilósofo holandês tem muito a contribuir não só para as igrejas brasileiras, mas também para a academia, impulsionando, assim, todo cristão a agir com responsabilidade biblicamente orientada no sentido de cumprir sua missão integral de influenciar e transformar em prol do bem comum a realidade sócio-cultural na qual está inserido. 


\section{REFERÊNCIAS}

ALMEIDA OLIVEIRA, Fabiano de. Philosophando Coram Deo: uma apresentação panorâmica da vida, pensamento e antecedentes intelectuais de Herman Dooyeweerd. Fides reformata, v. 11, n. 2, p. 73-100, 2006.

BANCEWICZ, Ruth. Epílogo. In: 0 teste da fé: os cientistas também creem. Trad. Guilherme de Carvalho. Viçosa - MG: Editora Ultimato, 2013.

CARVALHO, G. V. R.. Poder Político e Justiça Social na Filosofia Reformacional de Herman Dooyeweerd. Revista Eletrônica de Ética e Cidadania, Mackenzie, São Paulo, v. 1, n. 1, p. 30-50, 2005.

. Introdução Editorial. In.: DOOYEWEERD, Herman. No Crepúsculo do Pensamento: estudos sobre a pretensa autonomia da razão. São Paulo: Hagnos, 2010.

CAVALCANTI, Paulo Estevão Tavares. Percepção de Deus e justificação da crença religiosa: uma análise da epistemologia da religião de William Alston. 2010, 141f. Dissertação (Mestrado em Filosofia) - Universidade de Brasília, Brasília, 2010.

COMPARATO, Fábio Konder. Ética: direito, moral e religião no mundo moderno. São Paulo: Companhia das letras, 2006.

DOOYEWEERD, Herman. No crepúsculo do pensamento: estudos sobre a pretensa autonomia da razão. São Paulo: Hagnos. 2010.

DOOYEWEERD, Herman. Estado e Soberania: Ensaios sobre Cristianismo e Política. São Paulo: Vida Nova, 2014.

DUDLEY, Will. Idealismo alemão. Rio de Janeiro: Vozes Limitada, 2013.

MCDOWEL, Josh e MCDOWEL, Sean. Mais que um carpinteiro: a história desse livro pode transformar a história da sua vida. São Paulo: Hagnos, 2012

MOSCHETTA, Sílvia Ozelame Rigo. Teoria pós-moderna do direito de família na dimensão do plurarismo jurídico. 2016, 419f. Tese (Doutorado em Direito) - Centro de Ciências Jurídica, Universidade Federal de Santa Catarina, Florianópolis, 2016. 
MOUW, Richard J. Abraham Kuyper: A short and personal introduction. Wm. B. Eerdmans Publishing, 2011.

PIACENTEJUNIOR, José Carlos. Um estudo comparativo entre as propostas ético-sociais de $\mathbf{H}$. Dooyeweerd e N. Wolterstorff. Fides reformata, v. 17, n. 2, p. 45-73, 2012.

PINHEIRO, Maurício Mota Saboya. Experiência religiosa e garantia da crença na existência de Deus em Alvin Plantinga. Numen, v. 9, n. 1, 2010.

PORTUGAL, Agnaldo Cuoco. Epistemologia da experiência religiosa: Uma comparação entre Alston e Swinburne. Numen, v. 7, n. 2, 2004.

. Filosofia Analítica da Religião como Pensamento Pós-

" Pós-Metafísico". Horizonte, v. 8, n. 16, p. 80-98, 2010.

RAMOS, Leonardo; FREIRE, Lucas G. Introdução Editorial. In.: DOOYEWEERD, Herman. Estado e Soberania: Ensaios sobre Cristianismo e Política. São Paulo: Vida Nova, 2014.

WOLTERS, Albert. Redeemer College. Glossário. Traduzido e expandido por Guilherme de Carvalho in DOOYEWEERD, Herman. Estado e Soberania: Ensaios sobre Cristianismo e Política. São Paulo: Vida Nova, 2014. 